\title{
Differential Equations and Modeling of Dynamical Mechanical and Biomechanical Systems
}

\author{
Jan Awrejcewicz
}

Published online: 24 July 2012

(C) Foundation for Scientific Research and Technological Innovation 2012

The 11th International Conference devoted to "Dynamical Systems-Theory and Applications" hold in December 5-8, 2011 in Łódź, Poland, and it was organized by the staff of Department of Automation and Biomechanics of the Łódź University of Technology. It was financially supported by Rector of the Łódź University of Technology and Department of Education and Physical Culture of the Łódź City Hall.

Organizing Committee welcomed nearly 120 persons from 22 courtiers all over the world. Participants shared results of their research and experience of their theoretical and practical work in significant disciplines of mechanical engineering.

Scientific Committee of the conference included the following researchers: Marcilio Alves-São Paulo (Brazil), Igor V. Andrianov-Dnepropetrovsk (Ukraine), José M. Balthazar-Rio Claro (Brazil), Wojciech Blajer-Radom (Poland), Tadeusz Burczyński-Gliwice (Poland), Czesław Cempel-Poznań (Poland), Simona-Mariana Cretu-Craiova (Romania), Virgil-Florin Duma-Arad (Romania), Michal Fečkan-Bratislava (Slovakia), David Y. Gao-Blacksburg (USA), Józef Giergiel—Cracow (Poland), Peter Hagedorn—Darmstadt (Germany), Katica Hedrih-Niš (Serbia), Jan Kozanek—Prague (Czech Republic), Vadim A. Krysko-Saratov (Russia), Lidiya V. Kurpa-Kharkov (Ukraine), Claude-Henri Lamarque-Lyon (France), Gennady A. Leonov—St. Petersburg (Russia), Nuno M.M. MaiaLisbon (Portugal), Leonid I. Manevitch - Moscow (Russia), Bogdan Maruszewski-Poznań (Poland), Yuriy Mikhlin_Kharkov (Ukraine), Gerard Olivar-Manizales (Colombia), Bogdan Posiadała-Częstochowa (Poland), Bogusław Radziszewski-Kielce (Poland), Giuseppe Rega—Rome (Italy), Gábor Stépán-Budapest (Hungary), Jerzy Świder — Gliwice (Poland), Hans True-Lyngby (Denmark), Andrzej Tylikowski-Warsaw (Poland), Tadeusz Uhl—Cracow (Poland), Ferdinand Verhulst—Utrecht (The Netherlands), Jerzy WarmińskiLublin (Poland), Edmund Wittbrodt-Gdańsk (Poland), Józef Wojnarowski-Gliwice (Poland), Ludmila V. Yakushevich-Pushchino (Russia), Hamad M. Yehia-Mansoura (Egypt), Mikhail V. Zakrzhevsky—Riga (Latvia), Klaus Zimmermann—Ilmenau (Germany).

\footnotetext{
J. Awrejcewicz ( $\varangle)$

Department of Automation and Biomechanics, Lodz University of Technology,

1/15 Stefanowski Street, 90-924 Lodz, Poland

e-mail: awrejcew@p.lodz.pl
} 
Out of all papers recommended by Scientific Committee of the conference seventeen have been chosen to be presented in this special issue.

I do hope that many of the readers of DEDS will be attracted by topics included in this special issue.

I greatly appreciate both help and encouragement of the DEDS Editor Professor V. Sree Hari Rao to publish some of the papers recommended by Scientific Committee in this special issue after the standard review procedure.

Finally, I would like also to thank referees and Dr. P. Olejnik for his help in gathering of all manuscripts. 